\title{
Forensic Identification of Fake \& Genuine Saffron (Kesar) from Local Market of Greater Noida
}

ISSN: 2578-0042

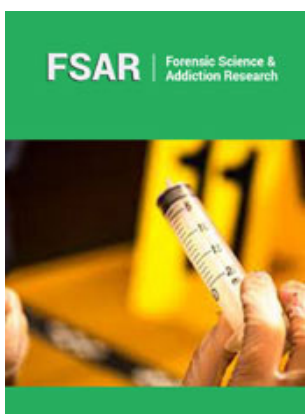

*Corresponding author: Mahipal Singh Sankhla, Research Scholar, Division of Forensic Science, India

Submission: November 12, 2019

Published: 㳑January 13, 2020

Volume 5 - Issue 2

How to cite this article: Kapil P, Kirti S, Mahipal S S, Rajeev K. Forensic Identification of Fake \& Genuine Saffron (Kesar) from Local Market of Greater Noida. Forensic Sci Add Res. 5(2). FSAR.000615.2020.

DOI: 10.31031/FSAR.2020.05.000615

Copyright@ Mahipal Singh Sankhla, This article is distributed under the terms of the Creative Commons Attribution 4.0 International License, which permits unrestricted use and redistribution provided that the original author and source are credited.

\author{
Kapil Parihar, Kirti Sharma, Mahipal Singh Sankhla* and Rajeev Kumar
}

Department of Forensic Science, India

\begin{abstract}
Saffron (Kesar) is one of the most expensive spices used all over the world. Having various properties, it is also used in herbal and traditional medicine. Because of its medicinal properties it is vastly in demand and so it became frequent object to being adulterated and faked. It is derived from the dried stigma of Crocus sativus flowers. This is rare and endangered plant that is the reason to fake saffron in local markets. The research study on forensically identification of the saffron by Chemical methods, microscopic and UVVisible Spectrophotometry instrument are used were performed on the saffron samples to explore rapid authenticity testing of genuine saffron. Saffron being adulterated by treating with colors and chemicals to give it genuine look and smell, which can cause toxicity (Figure 1)
\end{abstract}

Keywords: Saffron (Kesar); Adulterating; Toxicity; Forensic

\section{Introduction}

Kesar has been an important ingredient of the receipts of Vagbhata (500-100 B. C.) and Sushruta (700-600 B. C.) who practiced medicine. During second century B. C. Kalidas also referred to the occurrence of this plant in Kashmir [1]. Saffron is the processed stigma of the flower of Crocus sativus Linnaeus. It is having tremendous value in Spices as of its antiquity for colour, flavor and medicinal properties [2]. Saffron is also known as the king of all spices due to its flavor, aroma and color $[3,4]$. Saffron is a native of the southern Europe and is now produced by many countries like Spain, France, Italy, Germany, Iran and India [5]. In India Saffron producing state are Gujarat, Himachal Pradesh and Jammu and Kashmir [6]. The Forensic examination of the saffron and its products are a challenge to the examiners for determination of authenticity and detection of frauds Saffron, a dried sterile stigma of triploid plant Crocus sativus Linnaeus [7].

\section{Materials and Methods}

\section{Sampling}

5 different samples of saffron (1-5 gram) were collected from local market of Greater Noida which assumed to be low quality or fake and 1 sample from Jammu and Kashmir, which is genuine saffron. Preliminary organoleptic and microscopical investigation are conducted according to ISO-3636(2) 2010 (E) [8].

\section{Organoleptic examination}

Organoleptic investigation of the saffron samples involves the sense organs to test the characters such as colour, odour, size and shape to set up the preliminary identity of saffron [9]. Pure saffron gives yellow coloration in the solution of the water and methanol due to Carotenoid pigments-Crocin and Crocetin, but not in benzene, Xylene, ether, chloroform and toluene solution. Fake saffron imparts varieties of colour in different solvents. Genuine saffron yields pale yellow orange colour, while fake saffron imparts yellow colour in cotton soaked with polar solvent like water, methanol [10]. (Table 1 shows the organoleptic characteristics of saffron).

Color: Stigma is dark reddish to brown in color and style is yellowish brown to yellowish orange (Figure 2). 


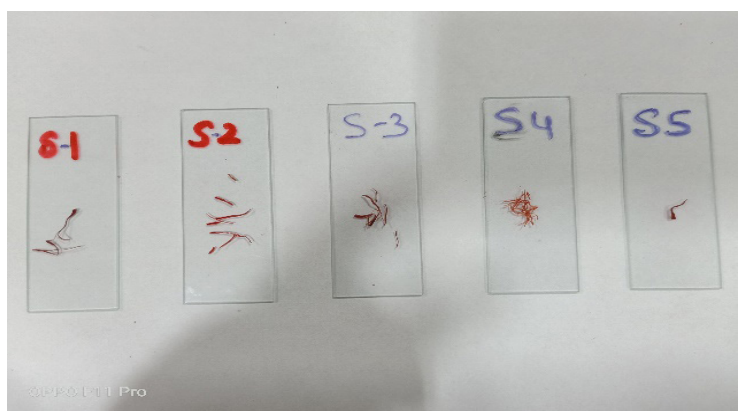

Figure 1: Visual examination of saffron samples.

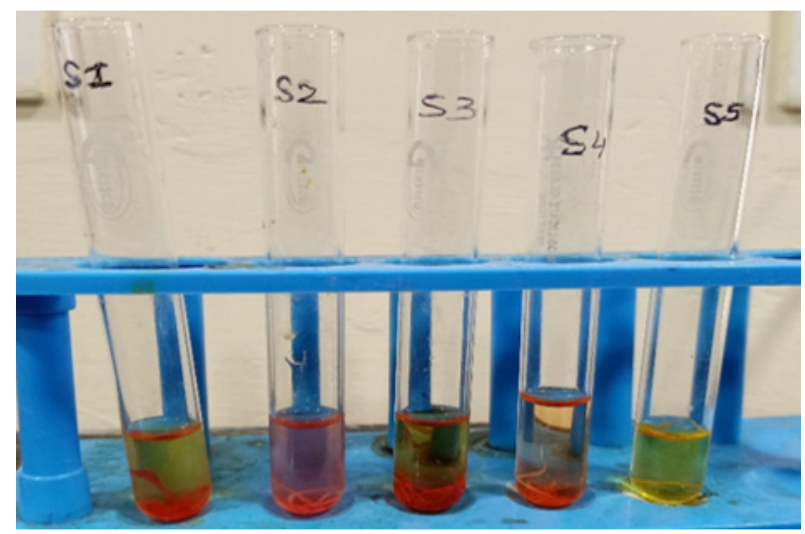

Figure 2: Color test of saffron in water and methanol.

Shape: Stigma trifid and styles cylindrical in shape [11].

\section{Chemical analysis}

Sulphuric acid test: The Carotenoid pigments like Crocin, Crocetin and Picocrocin reacts with the sulphuric acid to give bluish colour immediately, which finally changes to Violet to red, the reaction is due to the hydrolysis of the Carotenoid esters [12]. The sulphuric acid chemical test provides originality of the saffron to highest degree (Figures 3-12). On reaction of sulphuric acid, the genuine saffron produces blue colour immediately, while as fake saffron yields yellow colour [9]. Result shown in Figure 13.

Nitric acid test: Genuine saffron samples give light blue color with nitric acid result show in Figure 14

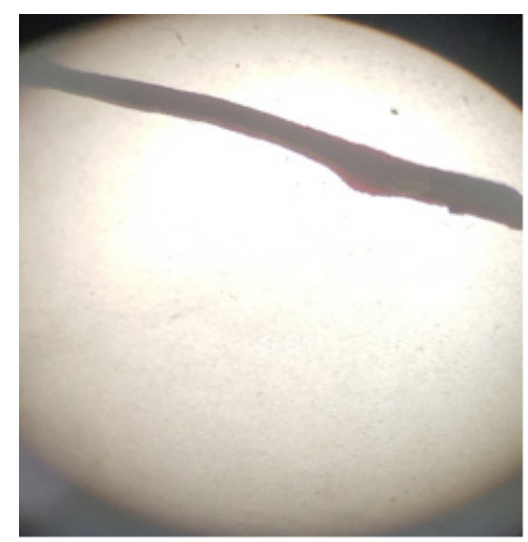

Figure 3: Sample 1 under compound microscope.

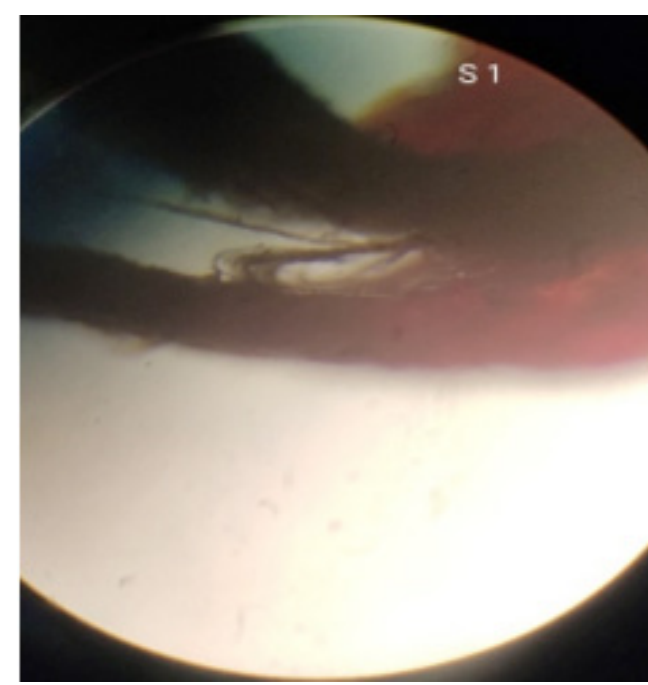

Figure 4: Sample 1 under stereomicroscope.

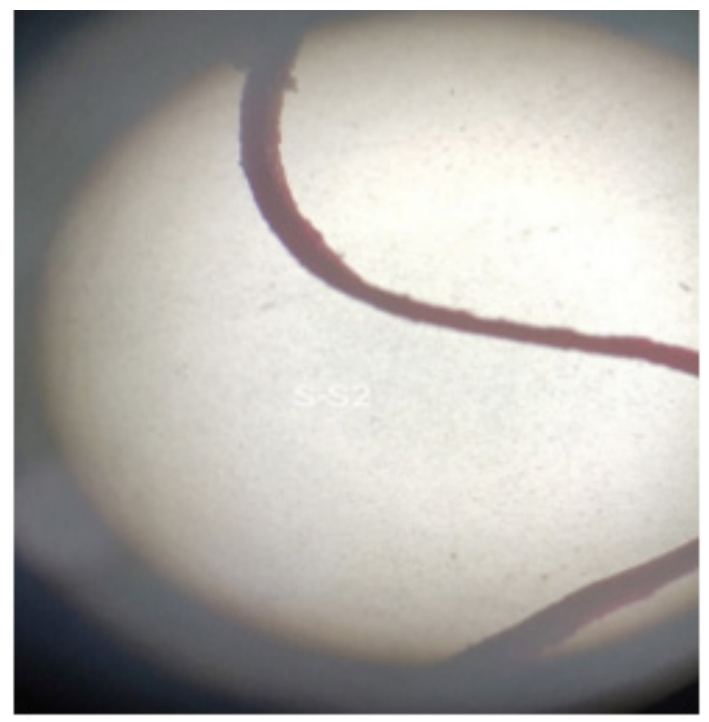

Figure 5: Sample 2 compound microscope.

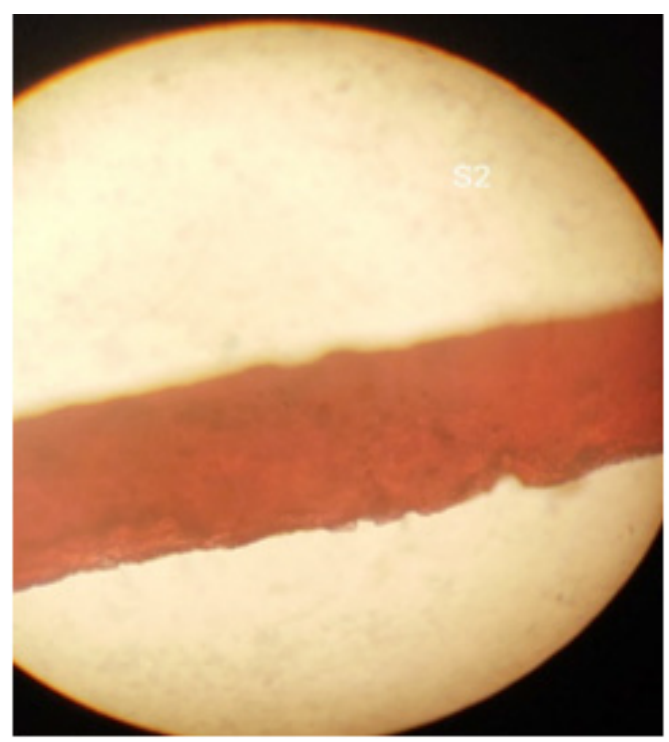

Figure 6: Sample 2 under stereomicroscope. 


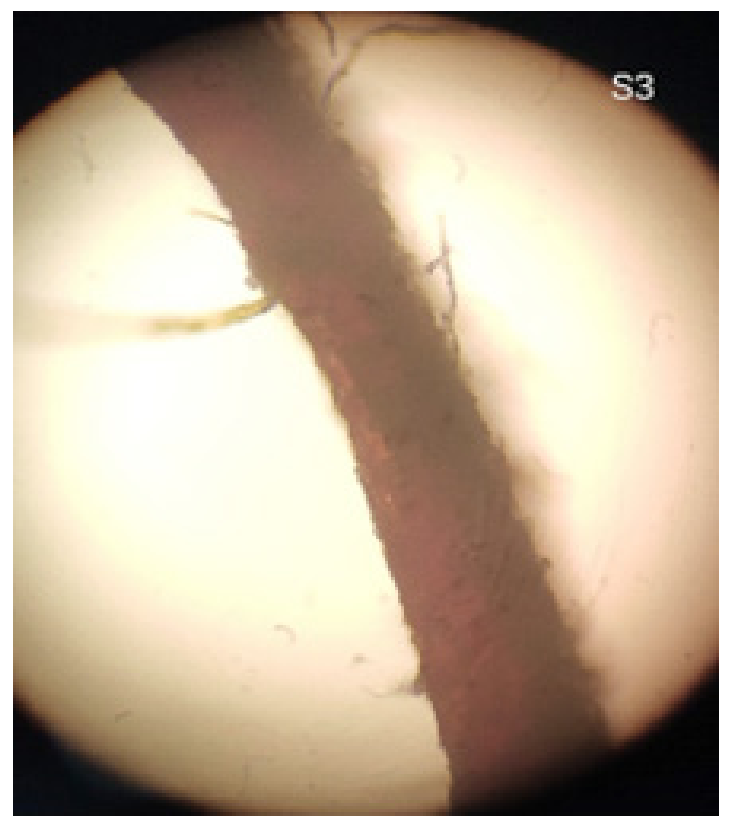

Figure 7: Sample 3 compound microscope.

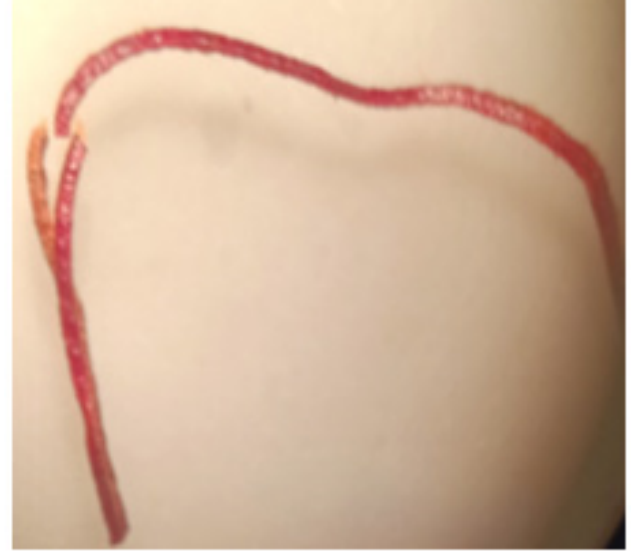

Figure 8: sample 3 under stereomicroscope.

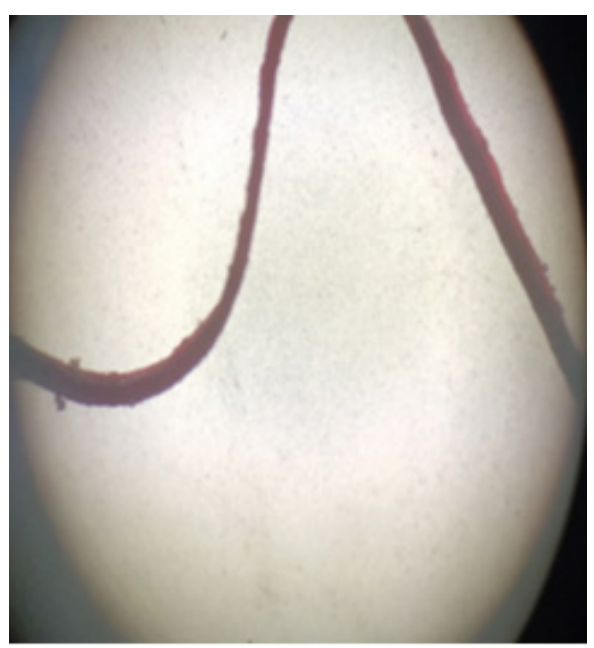

Figure 9: sample 4 under compound microscope.

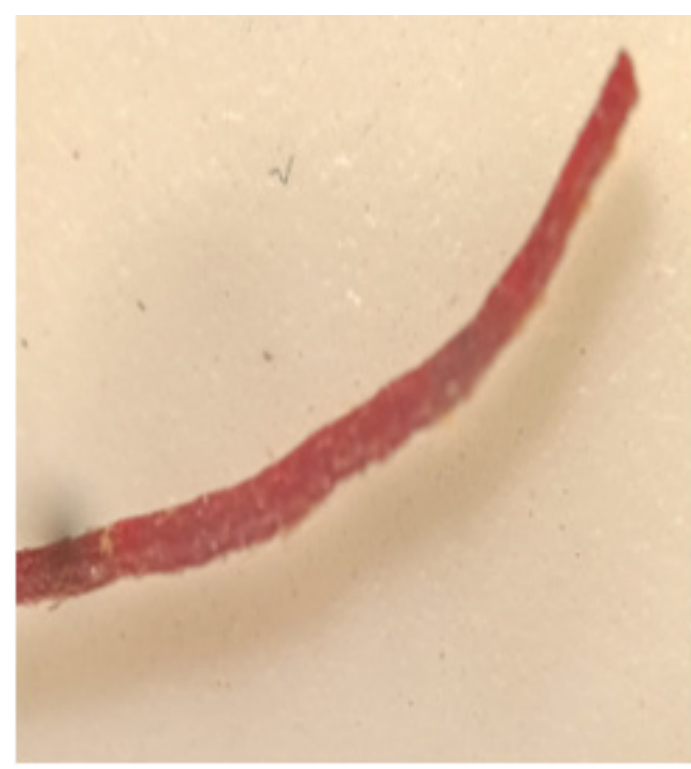

Figure 10: Sample 4 under stereomicroscope.

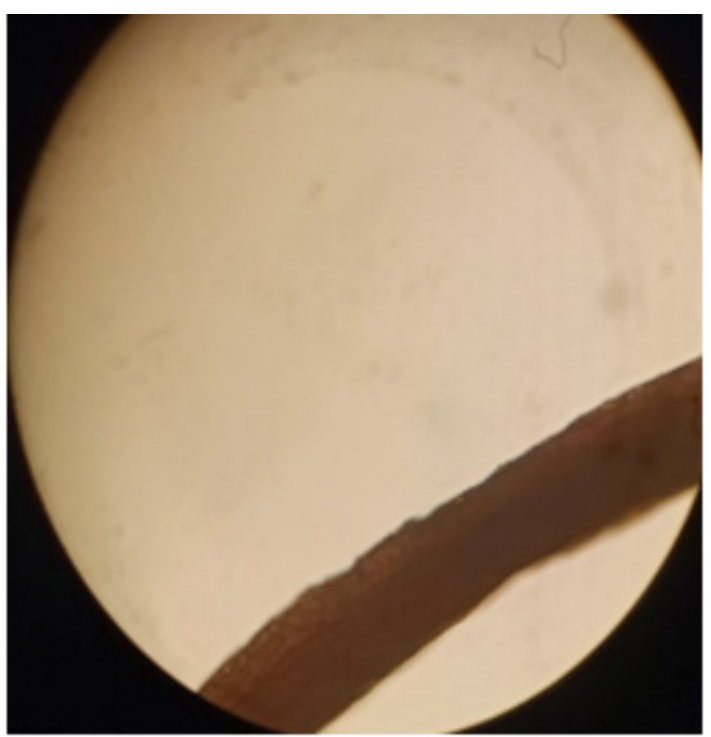

Figure 11: Sample 5 under compound microscope.

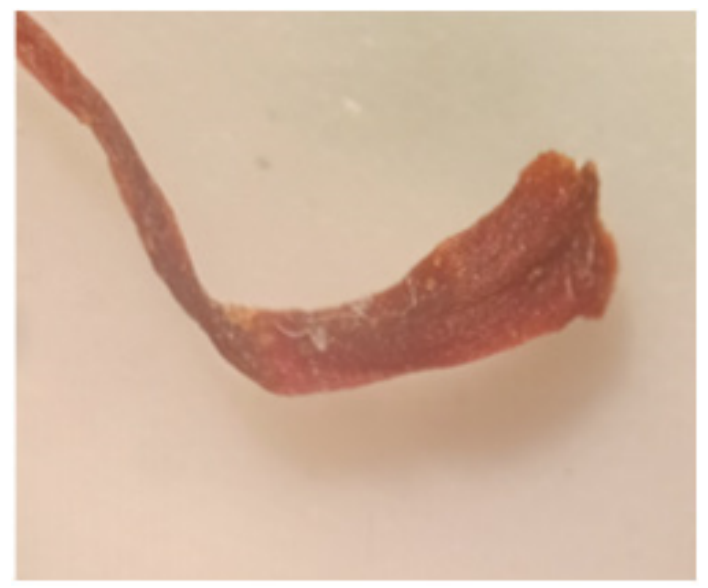

Figure 12: Sample 5 under compound microscope. 


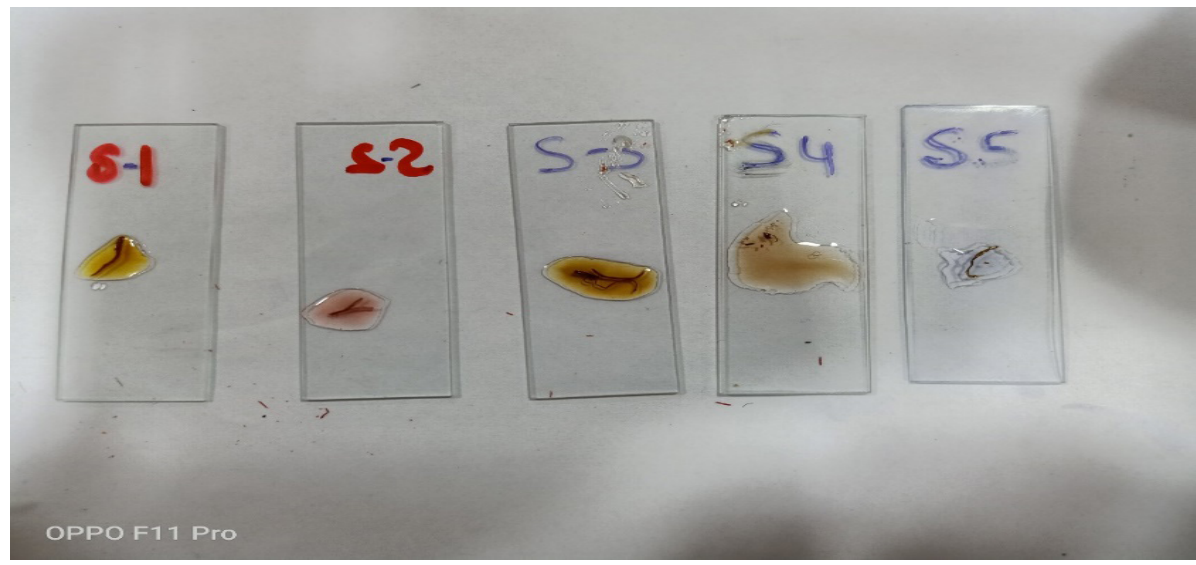

Figure 13: Chemical test of saffron samples in Sulphuric acid.

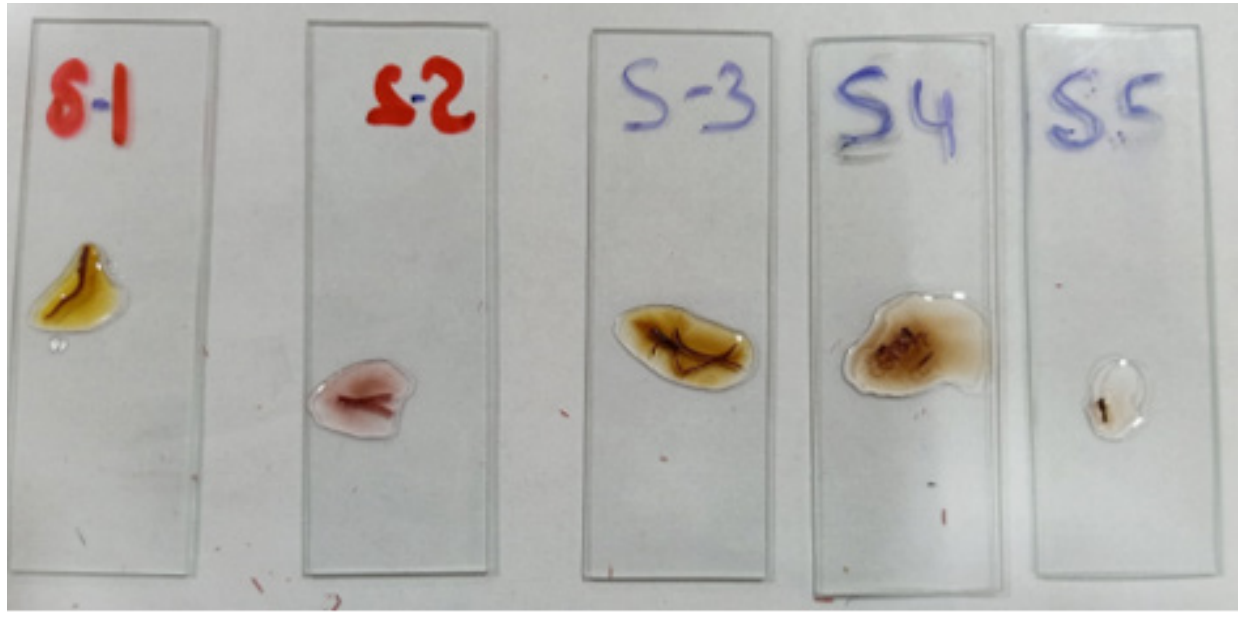

Figure 14:: Chemical test of saffron samples with nitric acid.

Table 1: Shows Organoleptic and color test of saffron.

\begin{tabular}{|c|c|c|c|c|}
\hline Sample no. & Condition & Color & Smell & Texture \\
\hline Sample 1 & Dried & Crimson red & No smell & Smooth \\
\hline Sample 2 & Dried & Crimson red & No smell & Rough \\
\hline Sample 3 & Dried & Crimson red & Pungent & Smooth \\
\hline Sample 4 & Dried & Crimson red & Synthetic & Smooth \\
\hline Sample 5 & Dried & Crimson red & Characteristic & Smooth \\
\hline
\end{tabular}

\section{Result \& Discussion}

These saffron were collected from local market of Greater Noida and were examined and use control sample of saffron are original Saffron J\&K. This samples were chemically and instrumentally analyzed to distinguish them genuine and fake saffron. In chemical reaction of components of the saffron (crocin, crocetin, picrocrocin) with acids like sulphuric acid and nitric acid yields indigo blue colour which forms rapid primary authenticity test. In instrumentation analysis of saffron it provides a significant information of genuine and fake saffron. The microscopic \& UV Visible Spectrophotometric analysis provides an information about the various anatomical characteristic features of genuine saffron and its adulterated form.

\section{Organoleptic colour test}

Microscopic examination: Features of entire saffron (stigma) are studied using compound light microscope at 10X and Stereomicroscope. saffron sample 1-4 are fake and sample 5 are original.

\section{Chemical test}

Sulphuric acid test: The sulphuric acid chemical test provides sample 1-4 are false result and sample 5 are show Positive result produces blue colour immediately, while as fake saffron yields yellow, red or brown colour. 
Nitric acid test: The Nitric acid chemical test provides sample 1-4 are false result and sample 5 are show Positive result produces light blue colour immediately, while as fake saffron yields yellow, red or brown colour.

UV-Visible spectrophotometer analysis: Calculation of the maximum wavelength of alcoholic extract of saffron samples using UV-Visible Double Beam Spectrophotometer 2201 SYSTRONICS $®$. The results obtained are shown in Table 2. Graph shows the absorbance of different saffron samples where genuine saffron shows highest absorbance.

Table 2: UV-Visible spectrophotometer result.

\begin{tabular}{|c|c|c|}
\hline Saffron & Wavelength & Absorbance \\
\hline Sample 1 & 213.2 & 0.072 \\
\hline Sample 2 & 227.6 & 0.058 \\
\hline Sample 3 & 202.4 & 0.017 \\
\hline Sample 4 & 201.2 & 0.03 \\
\hline Sample 5 & 287.6 & 0.077 \\
\hline
\end{tabular}

\section{Conclusion}

The saffron samples were analyzed using physical, chemical and instrumentation methods to forensically identify the authenticity of the saffron collected from the local markets. Color test and chemical tests were performed as preliminary test of genuine and fake saffron. However, instrumentation analysis using Spectrophotometer provides the further analysis giving graphical representation and differentiate the saffron on the basis of their absorbance shown by the graph which indicated that the genuine. This research shows that genuine saffron gives different color with sulphuric acid and nitic acid then others and also shows highest absorbance in UV Visible spectrophotometers.

\section{References}

1. Srivastava TN, Rajasekharan S, Badola DP, Shah DC (1985) Important medicinal plants of Jammu and Kashmir I Kesar (Saffron). Anc Sci Life 5(1): 68-73.

2. Grilli Caiola M, Canini A (2010) Looking for saffron (Crocus sativus L.) parents. Functional Plants Science and Biotechnology 4(2): 1-14.

3. Gohari AR, Saeidnia S, Mahmoodabadi MK (2013) An overview of saffron, phytochemicals and medicinal properties. Pharmacogn Rev 7(13): 61-66.

4. Srivastava R, Ahmed H, Dixit RK, Dharamveer, Saraf SA (2010) Crocus sativus L.: A comprehensive review. Pharmacogn Rev 4(8): 200-208.

5. Ordoudi SA, Tsimidou MZ (2004) Saffron quality: Effect of agriculture practices, Processing \& storage. Laboratory of Food Chemistry and Technology 1: 55-24.

6. Montalvo Hernandez B, Rito-Palomares M, Benavides J (2012) Recovery of crocins from saffron stigmas (Crocus sativus) in aqueous two-phase systems. J Chromatogr A 1236: 7-15.

7. Shukla SK, Iqbal M (2015) Forensic analysis of the saffron: Rapid authenticity testing. Int J Rese Appl Sci Eng Technol 3(4): 139-143.

8. IS0 3632-1 (2011) Species-saffron (crocus sativus l) part-2 test methods. The International Organization for Standards, Switzerland.

9. Orfanou O, Tsimidou M (1996) Evaluation of the coloring strength of saffron spice by UV-Vis spectrometry. Food Chemistry 57(3): 463-469.

10. Loskutov AV, Clifford B, Hosfield GL, Sink KC (2000) Development of an improved for extraction and quantitation of safranal in stigmas of Crocus sativus L. using HPLC. Food Chemistry 69(1): 87-95.

11. Kokate CK, Purohit AP, Gokhale SB (2006) Pharmacognosy. Nirali Prakashan, Pune, India, p. 390.

12. Tarantilis, Tsoupras G, Polissiou M (1995) determination of saffron (Crocus sativus L.) components in crude plant extract using HPLC, UV Photometer, diode-array MS. J Chromatogr A 699(1-2):107-118. 